\title{
Intravitreal Gene Therapy Reduces Lysosomal Storage in Specific Areas of the CNS in Mucopolysaccharidosis VII Mice
}

\author{
Anne K. Hennig, ${ }^{1}$ Beth Levy, ${ }^{4}$ Judith Mosinger Ogilvie, ${ }^{2,5}$ Carole A. Vogler, ${ }^{4}$ Nancy Galvin, ${ }^{4}$ Steven Bassnett, ${ }^{2}$ and \\ Mark S. Sands 1,3 \\ ${ }^{1}$ Department of Internal Medicine, Division of Stem Cell Biology, and Departments of ${ }^{2}$ Ophthalmology and Visual Sciences and ${ }^{3}$ Genetics, Washington \\ University School of Medicine, St. Louis, Missouri 63110, ${ }^{4}$ Department of Pathology, St. Louis University School of Medicine, St. Louis, Missouri 63107, and \\ ${ }^{5}$ Fay and Carl Simons Center for the Biology of Hearing and Deafness, Central Institute for the Deaf, St. Louis, Missouri 63110
}

\begin{abstract}
The mucopolysaccharidoses (MPSs) are lysosomal storage diseases resulting from impaired catabolism of sulfated glycosaminoglycans. MPS VII mice lack lysosomal $\beta$-glucuronidase (GUSB) activity, leading to the accumulation of partially degraded chondroitin, dermatan, and heparan sulfates in most tissues. Consequently, these mice develop most of the symptoms exhibited by human MPS VII patients, including progressive visual and cognitive deficits. To investigate the effects of reducing lysosomal storage in nervous tissues, we injected recombinant adeno-associated virus encoding GUSB directly into the vitreous humor of young adult mice. Interestingly, GUSB activity was subsequently detected in the brains of the recipients. At 8-12 weeks after treatment, increased GUSB activity and reduced lysosomal distension were found in regions of the thalamus and tectum that received inputs from the injected eye. Lysosomal storage was also reduced in adjacent nonvisual regions, including the hippocampus, as well as in the visual cortex. The findings suggest that both diffusion and trans-synaptic transfer contribute to the dissemination of enzyme activity within the CNS. Intravitreal injection may thus provide a means of delivering certain therapeutic gene products to specific areas within the CNS.
\end{abstract}

Key words: CNS; gene therapy; genetic diseases; inborn errors of metabolism; axonal transport; lysosomal storage reduction

\section{Introduction}

Lysosomal storage diseases are inherited disorders that are usually caused by decreased activity of one of the lysosomal acid hydrolases. Incompletely degraded substrate accumulates within lysosomes, interfering with cellular metabolism and eventually impairing the function of various organ systems. Progressive mental retardation, retinal degeneration, and other nervous system dysfunctions are common clinical features of many of these diseases in humans. Mice with mucopolysaccharidosis (MPS) type VII have a single base-pair deletion in exon 10 of the $\beta$-glucuronidase (GUSB) gene and consequently have no detectable GUSB (EC 3.2.1.31) activity (Birkenmeier et al., 1989; Sands and Birkenmeier, 1993). These mice show progressive impairment of most of the organ systems involved in human MPS VII (Vogler et al., 1990). Nervous system involvement includes progressive retinal degeneration with an accompanying decrease in electroretinogram amplitudes (Ohlemiller et al., 2000). Cognitive deficits likely result, at least in part, from lysosomal storage within the hippocampus and neocortex (Levy et al., 1996; O'Connor et al., 1998).

Several therapeutic strategies can prevent, delay, or decrease the severity of many of these symptoms in the MPS VII mouse (Vogler et al., 1998). Virus-mediated gene transfer therapy initi-

\footnotetext{
Received Sept. 9, 2002; revised Jan. 17, 2003; accepted Jan. 24, 2003

This work was funded by National Institutes of Health Grants 1R03 DC04946-01 (A.K.H.), DC 04665 (J.M.O.), EY 12260 (S.B.), DK 57586, and NS 044520 (M.S.S.) and by the National MPS Society (A.K.H.), the Foundation Fighting Blindness (J.M.O.), and Genzyme Corporation (M.S.S.).

Correspondence should be addressed to Dr. Mark S. Sands, Departments of Internal Medicine and Genetics, Washington University School of Medicine, Box 8007, 660 South Euclid Avenue, St. Louis, M0 63110. E-mail: msands@imgate.wustl.edu.

Copyright @ 2003 Society for Neuroscience $\quad 0270-6474 / 03 / 233302-06 \$ 15.00 / 0$
}

ated at birth is both effective and long lasting (Daly et al., 1999b, 2001; Frisella et al., 2001). However, because therapy is usually not initiated until after disease-related symptoms appear, we wanted to investigate whether reducing lysosomal storage actually improved function of nervous tissue or merely arrested progression of the dysfunction. Specifically, we injected an adenoassociated virus (AAV)-based gene therapy vector directly into the vitreous humor of young adult MPS VII mice with established lysosomal storage disease (A. K. Hennig, unpublished observations). One surprising finding with important therapeutic implications was that high levels of GUSB activity were detected in the optic nerve and tract. This activity decreased lysosomal storage within the thalamus, tectum, visual cortex, and neighboring brain areas, including the hippocampus. Therefore, this mode of administration might provide a means of delivering therapeutic agents to certain sites within the CNS.

\section{Materials and Methods}

Experimental animals and viral injections. MPS VII (mps/mps) and control $(m p s /+$ or $+/+)$ mice were produced by heterozygous matings of B6.C- $H-2^{b m l} /$ ByBir-gus ${ }^{m p s} /+$ mice, identified biochemically at birth, and genotyped at weaning as described previously (Sands et al., 1993; Wolfe and Sands, 1996). Mice at either 4 or 6 weeks of age were anesthetized with $80 \mathrm{mg} / \mathrm{kg}$ ketamine $/ 15 \mathrm{mg} / \mathrm{kg}$ xylazine. A 32 ga needle was inserted through the sclera just posterior to the ora serrata in the superotemporal quadrant. Three microliters of either recombinant AAV (AAV $\beta$ GEnh) or sterile tissue culture medium (Opti-MEM; Invitrogen) were slowly injected into the posterior chamber of the left eye. Antibiotic ophthalmic cream (Vetropolycin; Pharmaderm, Melville, NY) was applied to the eye after the injection.

The AAV $\beta$ GEnh vector consists of the human GUSB cDNA driven by a cytomegalovirus enhancer/chicken $\beta$-actin promoter cassette (Daly et al., 1999a). Viral stocks were prepared by the Gene Therapy Vector Core 

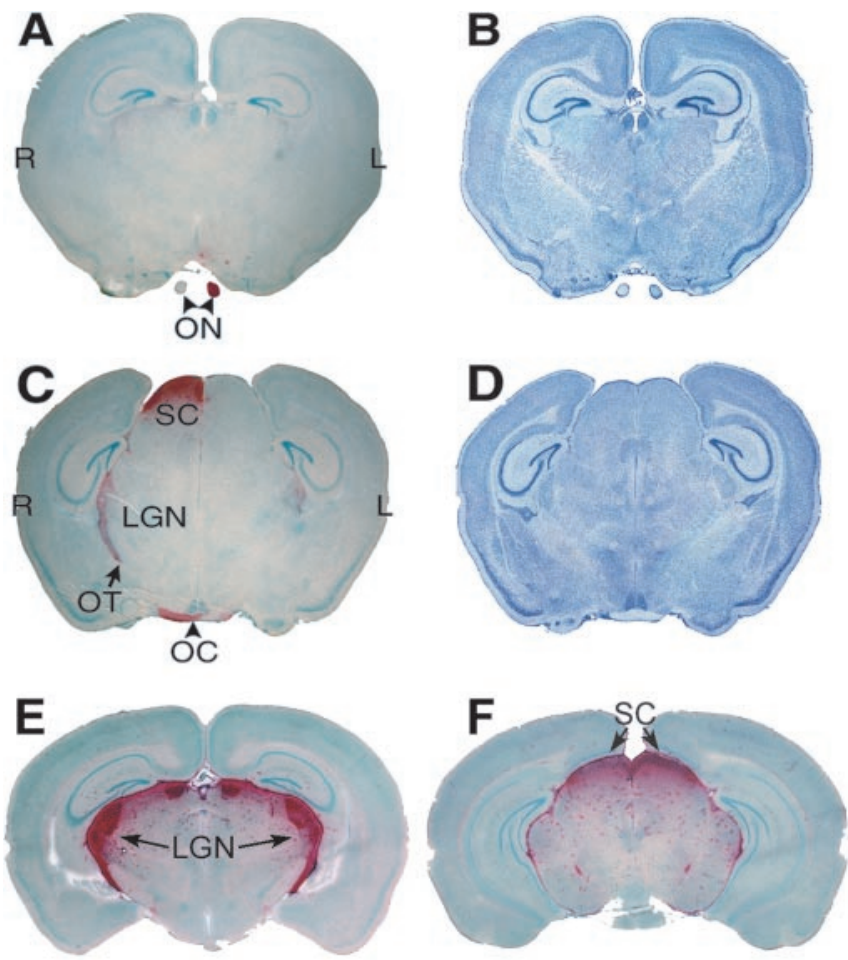

Figure 1. GUSB activity is present in the brain along the visual pathway. A, An oblique coronal section through the brain of an MPS VII mouse that received a unilateral intravitreal injection of AAV $\beta$ GEnh. GUSB activity (red) is present in the optic nerve (ON) from the mouse's left (injected) eye but not in the $0 \mathrm{~N}$ from the untreated right eye. $B$, An adjacent section stained with cresyl violet shows the cellular architecture. $C$, A parallel section through the optic chiasm $(\mathrm{OC})$ and tract $(\mathrm{OT})$, lateral geniculate nucleus (LGN), and superior colliculus $(\mathrm{SC})$ of the same brain shows prominent GUSB activity on the side contralateral to the injected eye, as well as a lower level of activity in the ipsilateral LGN. This pattern of enzyme activity was seen in all brains from MPS VII mice that received unilateral intravitreal AAV $\beta G E n h . D$, A section adjacent to that in C, stained with cresyl violet. $E$, A coronal section through the brain of an MPS VII mouse that received bilateral intravitreal $A A V \beta G$ Enh shows a symmetrical pattern of high-level enzyme activity. $F$, A parallel section from the same brain as $E$ shows high-level activity in both SCs. L, Mouse's left; $R$, mouse's right. Sections stained for GUSB activity are counterstained with methyl green.

Facility of the University of Florida, as described previously (Zolotukhin et al., 1999). Particle number and infectious units were determined by slot-blot analysis and infectious center assay, respectively. Each $3 \mu \mathrm{l}$ injection contained $1.5 \times 10^{7}$ infectious particles.

Biochemical, histological, and molecular analyses. Mice were killed by ketamine overdose $8(n=6)$ or $12(n=20)$ weeks after treatment, and eyes, optic nerves, brain, and other tissues were harvested. Homogenates were prepared from whole optic nerves or serial 2-mm-thick coronal sections of brains from four AAV $\beta$ GEnh-treated and two Opti-MEMtreated MPS VII mice 12 weeks after treatment, and four untreated MPS VII and four untreated normal littermates. GUSB activity was quantified as described by Wolfe and Sands (1996), and specific activity was expressed as nanomoles fluorescent 4-methylumbelliferone released per hour per milligram of total protein.

For GUSB histochemical localization, tissue samples were immersed in OCT compound (Sakura Finetek USA, Torrance, CA) and frozen on dry ice. GUSB activity was localized in $16 \mu \mathrm{m}$ (eye) or $40 \mu \mathrm{m}$ (brain) cryostat sections using the naphthol-ASBI- $\beta$-D-glucuronide/hexazotized pararosaniline histochemical stain as described by Wolfe and Sands (1996). Three-dimensional reconstruction of GUSB staining was performed on the brain of a 16-week-old MPS VII mouse that had received a single intravitreal injection of AAV $\beta$ GEnh in the left eye at 4 weeks of age. A contiguous series of $60-\mu \mathrm{m}$-thick coronal cryostat sections through the entire brain was stained for GUSB activity. Images were digitally captured, and a three-dimensional image was reconstructed using Vox Blast software (VayTek, Fairfield, CA).

Lysosomal storage in the CNS was evaluated at $8(n=1)$ or $12(n=2)$ weeks after treatment, corresponding to 14 or 16 weeks of age, respectively. One of the 12 week postinjection mice received bilateral intravitreal injections. Brains were immersion-fixed for at least $24 \mathrm{hr}$ in fresh $4 \%$ paraformaldehyde $/ 2 \%$ glutaraldehyde in PBS and divided along the midsagittal fissure, and the right halves were cut in coronal slices (see Table 2 ). The slices were postfixed in osmium tetroxide and embedded in Spurr's resin. Toluidine blue-stained $0.5-\mu \mathrm{m}$-thick sections were evaluated for evidence of lysosomal storage in leptomeninges (pia-arachnoid), intraparenchymal perivascular cells, neurons, and microglial cells. Lysosomal storage was evaluated in the visual and nonvisual inferolateral parietal lobe and frontal lobe of the neocortex, hippocampal areas CA1 through CA4, dorsal brainstem, and the dorsolateral central gray matter. Reduction of storage was determined by comparison with age-matched untreated and Opti-MEM-treated normal and MPS VII brains. A brain from a normal AAV $\beta$ GEnh-treated littermate was also examined.

PCR analysis was performed on cryostat sections from three 16-weekold, unilaterally treated MPS VII mice, using primers specific for exons 6 and 7 (Daly et al., 1999a). These primers amplify a 240 bp fragment from the human GUSB cDNA and, less efficiently, a $454 \mathrm{bp}$ fragment from the mouse GUSB gene. The sensitivity of this assay was determined by titering mouse fibroblasts (3521 cells) (Sands and Birkenmeier, 1993), which contain a single retrovirally inserted copy of the human GUSB cDNA with nontransduced 3521 cells. Cell pellets containing $4 \times 10^{6}$ cells were prepared and tested the same as cryostat sections.

\section{Results}

After intravitreal injection of AAV $\beta$ GEnh, GUSB enzyme activity was noted in the optic nerve, chiasm, and tract, the lateral geniculate nucleus (LGN) of the thalamus, and the superior colliculus (SC) contralateral to the injected eye of treated MPS VII mice

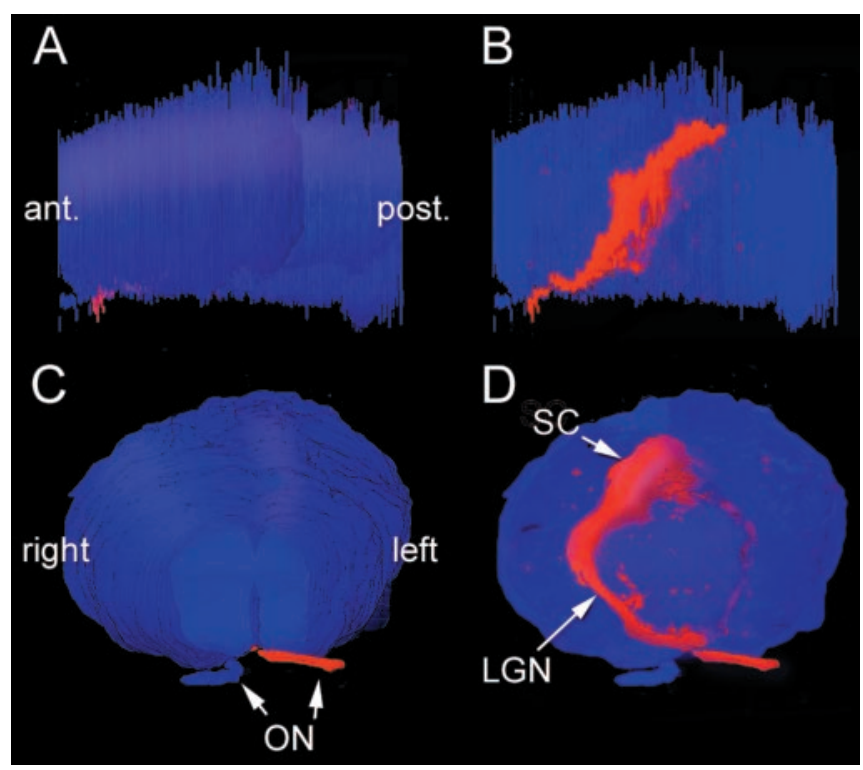

Figure 2. The distribution of GUSB activity throughout the brain is seen in a threedimensional reconstruction from another 16-week-old MPS VII mouse treated unilaterally with intravitreal AAV $\beta$ GEnh at 4 weeks of age. $A$, Lateral view of the reconstructed image shows surface contours of the cerebral hemisphere, cerebellum, and brainstem, from anterior (ant.) to posterior (post.). $B$, Rendering the image transparent shows the pattern of GUSB activity along the visual pathway. C, Frontal view, showing the surface contours of the reconstruction. The right (blue) and left (red) optic nerves (ON) can be seen entering the brain. Right and left indicate the right and left sides of the mouse. D, In the transparent image, GUSB activity is most prominent in the optic nerve and tract, lateral geniculate nucleus (LGN), and superior colliculus (SC) on the right side, contralateral to the injected eye. Lower levels of activity can also be seen in the ipsilateral optic pathway. 
TABLE 1: GUSB specific activity in $2 \mathrm{~mm}$ thick slices of brain from individual MPS VII mice treated with intravitreal injection of adeno-associated virus.

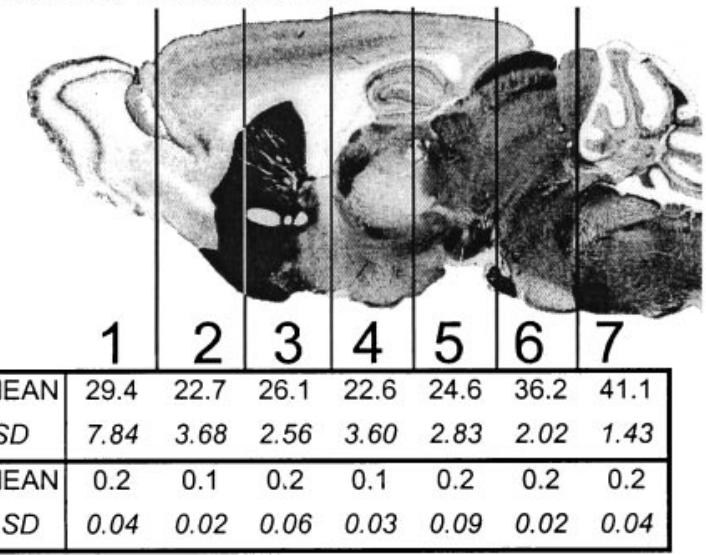

\begin{tabular}{|c|c|c|c|c|c|c|c|}
\hline $\begin{array}{l}\text { MPSVII contra } \\
+\end{array}$ & 0.2 & 0.2 & $<0.1$ & 0.6 & 2.6 & 0.3 & 0.2 \\
\hline AAV $\beta G$ ipsi & 0.2 & 0.3 & 0.4 & 0.2 & 0.4 & 0.2 & 0.1 \\
\hline $\begin{array}{l}\text { MPSVII contra } \\
+\end{array}$ & 0.1 & $<0.1$ & 0.2 & 0.5 & 0.7 & 0.8 & nd \\
\hline$A A V \beta G \quad$ ipsi & 0.1 & 0.1 & 0.1 & 0.2 & 0.2 & 0.1 & nd \\
\hline $\begin{array}{l}\text { MPSVII contra } \\
+\end{array}$ & $<0.1$ & 0.3 & 0.8 & 1.2 & 0.2 & 0.1 & 0.2 \\
\hline$A A V \beta G$ & 0.1 & 0.6 & 0.5 & 0.2 & 0.2 & $<0.1$ & 0.4 \\
\hline $\begin{array}{c}\text { MPSVII contra } \\
+\end{array}$ & 0.2 & 0.2 & 1.1 & 3.9 & 4.2 & 0.4 & 0.2 \\
\hline AAV $\beta G \quad$ ipsi & 0.1 & 0.2 & 1.2 & 1.3 & 0.8 & 0.3 & 0.1 \\
\hline
\end{tabular}

SD: one standard deviation; contra: brain sections contralateral to the injected eye; ipsi: sections from the same side as the injected eye. Numbers in bold indicate values greater than 2.5 times the mean of the untreated MPS VII values for that section. nd: not tested.

(Fig. 1). Mice that received bilateral injections of virus showed symmetrical distributions of enzyme activity. GUSB activity within the entire brain of one randomly chosen, unilaterally AAV $\beta$ GEnh-treated MPS VII mouse was visualized by threedimensional reconstruction of images from serial cryostat sections (Fig. 2). Posterior to the optic chiasm, GUSB activity extends dorsally around the lateral edges of the thalamus, where axons of the optic tract travel to reach the LGN. On the side of the brain contralateral to the injected eye, enzyme activity continues dorsally and posteriorly through the LGN and then medially to the SC in the dorsal brainstem between the cortex and the cerebellum. Similar enzyme activity patterns were seen in all brains examined from AAV $\beta$ GEnh-treated MPS VII mice 4 weeks $(n=$ $3), 8$ weeks $(n=4)$, or 12 weeks $(n=5)$ after injection. No enzyme activity was found in brains from MPS VII mice injected with culture medium.

The amount of GUSB enzyme activity present 12 weeks after treatment was quantified in 2-mm-thick coronal slices from right or left half-brains (Table 1). Although the specific activity levels varied among the AAV $\beta$ GEnh-treated mice, all showed substantial increases in GUSB activity in the contralateral brain slices between the optic chiasm and the posterior end of the superior colliculus compared with untreated MPS VII littermates. The treated mouse with the highest contralateral activity levels also had a detectable increase in GUSB activity on the ipsilateral side of the brain. Specific activity levels ranged from 2.3 to $17 \%$ of
TABLE 2: Reduction in lysosomal storage in the brains of MPS VII mice treated with intra-vitreal injection of adenoassociated virus.

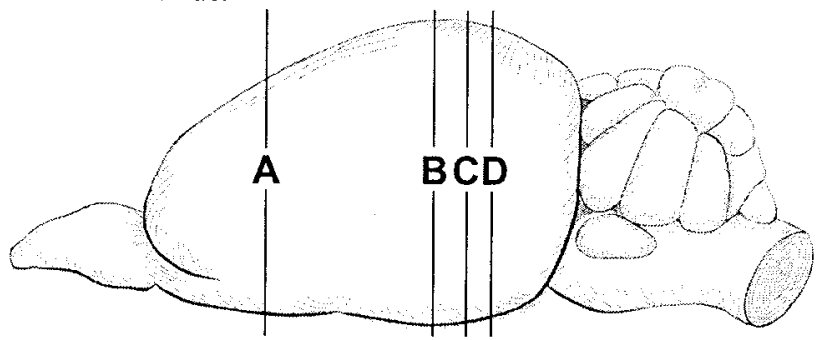

\begin{tabular}{|l|c|c|c|}
\hline TIME: & $\begin{array}{c}8 \text { wk post } \\
\text { injection } \\
\text { INJECTION: }\end{array}$ & \multicolumn{2}{|c|}{$\begin{array}{c}12 \text { wk post } \\
\text { injection }\end{array}$} \\
\cline { 3 - 4 } & Unilateral & Unilateral & Bilateral \\
\hline $\begin{array}{c}\text { Leptomeninges } \\
\text { (pia-arachnoid) }\end{array}$ & NC & $\downarrow$ & $\downarrow$ \\
\hline Perivascular cells & NC & NC & $\downarrow$ \\
\hline $\begin{array}{l}\text { Hippocampus CA 3- } \\
4 \\
\text { neurons and glia }\end{array}$ & $\downarrow$ & $\downarrow$ & $\downarrow$ \\
\hline $\begin{array}{l}\text { Hippocampus CA 1- } \\
2\end{array}$ & NC & NC & $\downarrow$ \\
\hline neurons and glia & & & \\
\hline $\begin{array}{c}\text { Visual neocortex } \\
\text { neurons and glia }\end{array}$ & $\downarrow$ & $\downarrow$ & $\downarrow$ \\
\hline Frontal neocortex & $\mathrm{NC}$ & $\mathrm{NC}$ & $\mathrm{NC}$ \\
\hline Central gray /LGN & $\mathrm{NC}$ & $\downarrow$ & $\downarrow$ \\
\hline Brainstem /SC & $\downarrow$ & $\downarrow$ & $\downarrow$ \\
\hline Ependyma & $\mathrm{NC}$ & $\mathrm{NC}$ & $\mathrm{NC}$ \\
\hline
\end{tabular}

The drawing indicates the positions of coronal sections used for histopathologic evaluation. Section A includes frontal cortex, ependyma, and central gray/lateral geniculate. Section B includes visual cortex, brainstem/lateral geniculate, and hippocampus. Section C includes visual neocortex, hippocampus, and brainstem/superior colliculus. Section D includes hippocampus and brainstem/superior colliculus. NC: no reduction in storage compared to sham treated MPS VII mouse; $\downarrow$ : reduction in storage in at least one of the four sections indicated on the figure.

normal levels, substantially lower than those of normal littermates. This is consistent with the localization of enzyme activity to discrete subregions of the brain seen histochemically.

Histopathologic examination was performed to assess lysosomal storage in the brains of treated and untreated mice (Table 2, Fig. 3). In the central gray (thalamic) and dorsal brainstem (tectal) nuclei of untreated MPS VII mice, lysosomal distension in neuronal somata was slight, whereas storage in glial cells was more prominent (Fig. 3). In the treated mice, storage was reduced in areas corresponding to both the LGN and the SC (Table 2). In the visual cortex, lysosomal storage was reduced in both neurons and microglia in the more posterior sections examined. In contrast, in the more anterior visual cortex and the adjacent inferolateral parietal cortex, no reduction in storage was apparent at the light microscopic level. In general, although the decrease in storage was more conspicuous in glial cells than in neurons, both cell populations showed similar responses in each area examined.

In the hippocampus of treated mice, the CA3-CA4 regions, 

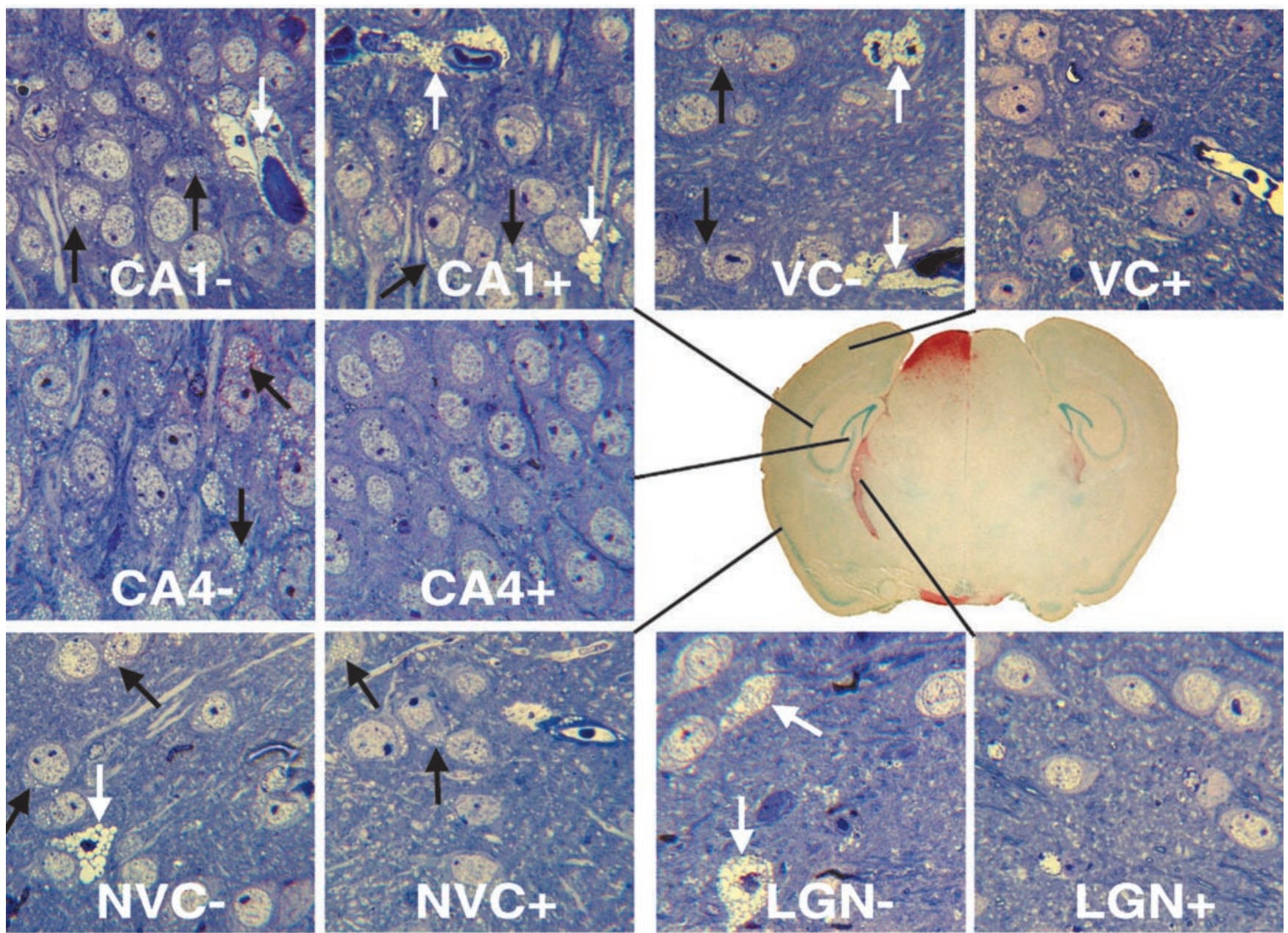

Figure 3. Intravitreal AAV $\beta$ GEnh decreases lysosomal storage in hippocampus and visual cortex as well as LGN. Pairs of toluidine blue-stained, $0.5-\mu \mathrm{m}$-thick sections from the CA1 and CA4 regions of the hippocampus, visual cortex (VC), nonvisual cortex (NVC), and lateral geniculate nucleus (LGN) are from two 16-week-old MPS VII mice. The sections indicated by " -" are from the mouse that received no treatment. The sections indicated by " + " are from a littermate that received unilateral intravitreal AAV $\beta$ GEnh at 4 weeks of age. Black arrows indicate distended vacuoles in neurons; white arrows indicate storage in microglia and other nonneuronal cells. The approximate sites of the respective histologic samples are indicated on the GUSB-stained cryostat section.

which are in dorsal proximity to the LGN, had reduced neuronal and microglial storage more frequently than the CA1-CA2 regions, which are farther from the visual pathway (Fig. 3). Only the bilaterally injected MPS VII mouse showed improvement in the CA1-CA2 regions. Storage was reduced in the leptomeninges (pia-arachnoid) in both of the 12 week postinjection mice examined, but perivascular cells were cleared only in the mouse that received bilateral injections. No reduction in storage was seen in the ependyma.

Spheroids are morphologic alterations in neuronal processes indicative of axonal degeneration. They have previously been described in animal models of several lysosomal storage diseases including MPS VII (Levy et al., 1996; Walkley, 1998). All of the AAV $\beta$ GEnh-treated mice that were examined had spheroids in the central white matter, neocortex, central gray matter, and hippocampal pyramidal cell layer. The distribution patterns were similar to those seen in untreated and saline-treated MPS VII control mice. Thus, MPS VII mice that received intravitreal AAV $\beta$ GEnh treatment showed less lysosomal storage than untreated MPS VII mice of the same age, but they still had other morphologic alterations associated with MPS VII. The functional significance of this finding is unclear.

To investigate whether the GUSB activity present in the brains of the treated mice was being produced locally, PCR amplification of GUSB sequences was performed on DNA extracted from cryostat sections adjacent to those stained for enzyme activity. The primers preferentially amplify a $240 \mathrm{bp}$ fragment from the human cDNA present in the AAV genome, but they also produce a $454 \mathrm{bp}$ fragment from the endogenous mouse GUSB gene. When tissue from a representative injected animal was examined, the $240 \mathrm{bp}$ AAV genome-specific fragment was amplified only from DNA obtained from tissue sections through treated eyes (Fig. 4A). The $454 \mathrm{bp}$ mouse genomic GUSB product, but no AAV genome-specific fragment, was amplified from the untreated right eye, the optic nerve exiting the treated eye, and brain coronal sections through the optic chiasm, LGN, or SC. Similar results were obtained from two additional injected animals analyzed in the identical manner. This assay as performed detects as little as one copy of the human cDNA in $\sim 2,000-10,000$ haploid mouse genomes (Fig. 4B).

\section{Discussion}

The retina is a readily accessible CNS structure containing neurons that project to the thalamus and tectum. Many substances including proteins, chemical tracers, and small precursor molecules are transported along these projections when injected into 


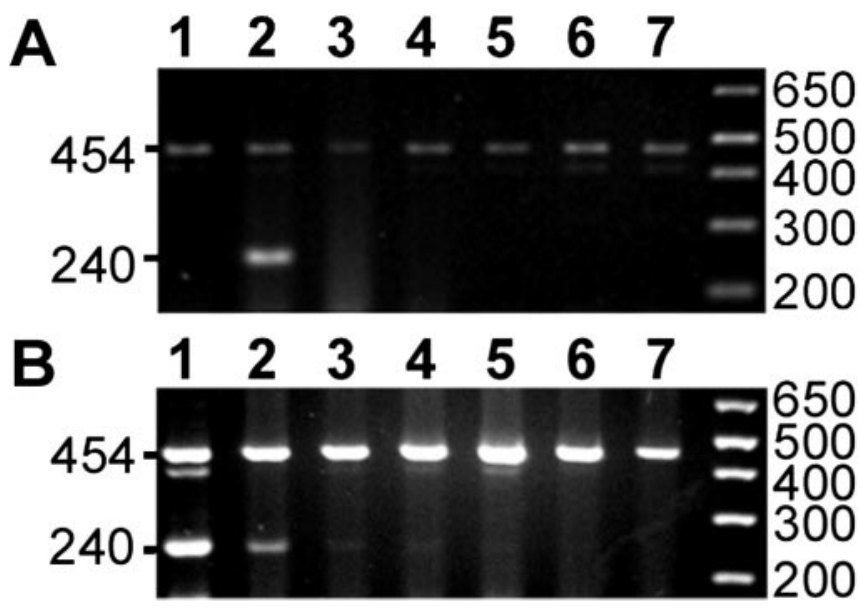

Figure 4. $\quad P C R$ reveals $A A V \beta G E$ Enh DNA in the injected eyes of treated mice, but not in brain samples. $A$, DNA from the right optic nerve (lane 1), left (injected) eye (lane 2), left optic nerve (lane 3), optic chiasm (lane 4), right LGN (lane 5), posterior LGN + anterior SC (lane 6), and SC (lane 7) of a 14-week-old MPS VII mouse that received an intravitreal injection at 6 weeks of age. Primers amplified a fragment of $240 \mathrm{bp}$ from the human GUSB cDNA sequence encoded by AAV $\beta$ GEnh as well as a $454 \mathrm{bp}$ fragment from the endogenous mouse GUSB gene. $B$, Murine fibroblasts (3521 cells) containing one retroviral hGUSB CDNA insert per cell (lane 1) were titered with untransduced 3521 cells (lane 7). Cell mixtures contained one copy of hGUSB per 100 haploid genomes (lane 2), one per $1 \times 10^{3}$ (lane 3), one per $2 \times 10^{3}$ (lane 4 ), one per $10^{4}$ (lane 5 ), and one per $2 \times 10^{4}$ (lane 6). Fragment sizes are given in base pairs.

the posterior chamber of the eye (Grafstein and Forman, 1980). In a recent study, green fluorescent protein (GFP), a cytoplasmic marker, was transported in an anterograde direction after AAVmediated gene transfer to the eye (Dudus et al., 1999). The findings presented here demonstrate that retinal expression of a noncytoplasmic protein (a lysosomal enzyme) results in enzyme activity appearing in the thalamus and tectum in levels sufficient to reduce disease pathology in these and adjacent areas. The unequal distribution of enzyme activity between the two hemispheres in unilaterally injected animals is consistent with the low percentage of retinotectal fibers that innervate the ipsilateral primary visual nuclei in mice (Drager, 1985). Axonal transport of the protein rather than the virus seems to account for most of the activity in the brain, because the amount of vector genome in the CNS areas with the highest amounts of enzyme activity was at most extremely low. Because of the limitations of the PCR assay, however, small amounts of AAV might also be transported to the brain and could account for some of the activity.

Substantial clearance of lysosomal storage was observed in the LGN and SC of all AAV $\beta$ GEnh-treated mice that were examined. The visual cortex also showed some reduction in neuronal storage at the later survival times. This suggests that therapeutic enzyme activity can be transported across synapses in the LGN, because there are no direct axonal connections from the retina to the visual cortex. Interestingly, adjacent nonvisual regions of the thalamus and tectum also showed a marked decrease in lysosomal storage. Furthermore, the hippocampus, which does not receive direct visual input, showed consistent decreases in lysosomal storage in the CA3-CA4 regions, which are in dorsal proximity to the LGN. The CA1-CA2 regions (which are farther from the visual pathway) also showed decreases in lysosomal storage in the mouse that received bilateral gene therapy. Taken together, these findings suggest that GUSB enzyme activity spreads within the brain by both neuronal transport and diffusion.

Although lysosomal storage was reduced in MPS VII mouse brains after intravitreal injection of an AAV vector, the reduction was limited to specific regions. This may be somewhat surprising, because previous reports have shown that a single intracranial injection of vector will reduce storage throughout most of the treated hemisphere and partially correct the contralateral hemisphere (Ghodsi et al., 1998; Skorupa et al., 1999; Bosch et al., 2000; Sferra et al., 2000). This difference may be attributable to the fact that higher levels of enzyme activity are delivered to the brain by direct intracranial injection compared with transport from the eye. It is possible that the mechanism responsible for transport from the retina has a limited capacity, resulting in a lower steady-state level of enzyme activity in the brain. Another factor that may contribute to the difference could be that the myelin sheaths surrounding the ganglion cell axons may limit the diffusion of GUSB, thereby limiting the area of correction.

It has previously been shown that lysosomal storage reduction correlates both with the prevention of cognitive deficits after neonatal gene therapy and with the reversal of established CNS deficits after gene therapy in adult animals. The Morris water maze was used to correlate the reduction of lysosomal distension in the CNS with improved cognitive function in MPS VII mice treated at birth with intracranial gene therapy (Frisella et al., 2001). In addition, Brooks et al. (2002) have used a repeated acquisition performance chamber to demonstrate that after lentiviralmediated gene therapy into the CNS of adult MPS VII mice, the reduction of lysosomal storage in the brain leads to improvements in cognitive function. Although in the current study lysosomal storage was reduced in several areas of the brain including the hippocampus, it was unclear whether cognitive functions were improved. The progression of systemic disease in the MPS VII mice at the endpoint of this study precluded behavioral testing. However, it will be critical to determine the extent of cognitive recovery after intravitreal gene delivery.

Therapies directed to the CNS are usually delivered by direct injection. Intracranial injections of adenoviral (Ghodsi et al., 1998; Stein et al., 1999), AAV (Skorupa et al., 1999; Sferra et al., 2000; Frisella et al., 2001; Fu et al., 2002), and lentiviral (Bosch et al., 2000; Brooks et al., 2002) vectors have been used for treating CNS lysosomal storage disease. Two recent studies have addressed transport of gene products within the CNS after AAVmediated gene transfer to specific brain nuclei. Chamberlin et al. (1998) found robust anterograde labeling of transduced neurons, but essentially no retrograde transport after injecting an AAV construct encoding GFP into the parabrachial nucleus in the brainstem. Passini et al. (2002) injected AAV encoding GUSB into the hippocampus or the striatum of MPS VII brains and reported enzyme transport throughout the septohippocampal and nigrostriatal systems with concomitant reversal of lysosomal storage. Here we show that intravitreal injection also results in targeting of therapeutic gene product to specific subregions of the brain. Axonal transport of the GUSB gene product is likely involved at least in the correction of the visual cortex, because no ASBI reactivity, indicating transduced cells producing high levels of enzyme, were ever seen in this area in any of the brains examined.

Successful axonal transport of therapeutic gene products from a remote administration site into the CNS requires that the gene product be recognized as suitable cargo, released from the transporting cell at axon terminals, and taken up and used correctly by adjacent, affected cells. Soluble lysosomal enzymes are ideally suited for this approach because all cells possess mechanisms for exchanging these enzymes in a receptor-dependent manner through a process referred to as "cross-correction" (Neufeld and 
Fratantoni, 1970; Kornfeld, 1992). Other gene products that might be appropriate for this delivery system include secreted growth factors and other cytokines.

The findings presented here show that axonal transport from the retina can be used to deliver therapeutic agents into the brain. If these findings hold true in larger animals, this route of entry into the CNS may provide a less invasive delivery method for certain therapeutic gene products. Such a treatment strategy might be particularly attractive for lysosomal storage diseases, during which both visual and cognitive deficits occur, and may reduce the number of intracranial injections required for widespread CNS therapy.

\section{References}

Birkenmeier EH, Davisson MT, Beamer WG, Ganschow RE, Vogler CA, Gwynn B, Lyford KA, Maltais LM, Wawrzyniak CJ (1989) Murine mucopolysaccharidosis type VII: characterization of a mouse with $\beta$-glucuronidase deficiency. J Clin Invest 83:1258-1266.

Bosch A, Ferret E, Desmaris N, Trono D, Heard JM (2000) Reversal of pathology in the entire brain of mucopolysaccharidosis type VII mice after lentivirus-mediated gene transfer. Hum Gene Ther 11:1139-1150.

Brooks AI, Stein CS, Hughes SM, Heth J, McCray Jr PM, Sauter SL, Johnston JC, Cory-Slechta DA, Federoff HJ, Davidson BL (2002) Functional correction of established central nervous system deficits in an animal model of lysosomal storage disease with feline immunodeficiency virus-based vectors. Proc Natl Acad Sci USA 99:6216-6221.

Chamberlin NL, Du B, de Lacalle S, Saper CB (1998) Recombinant adenoassociated virus vector: use for transgene expression and anterograde tract tracing in the CNS. Brain Res 793:169-175.

Daly T, Okuyama T, Vogler C, Haskins M, Muzyczka N, Sands MS (1999a) Neonatal intramuscular injection with recombinant adeno-associated virus results in prolonged $\beta$-glucuronidase expression in situ and correction of liver pathology in mucopolysaccharidosis type VII mice. Hum Gene Ther 10:85-94.

Daly TM, Vogler C, Levy B, Haskins ME, Sands MS (1999b) Neonatal gene transfer leads to widespread correction of pathology in a murine model of lysosomal storage disease. Proc Natl Acad Sci USA 96:2296-2300.

Daly TM, Ohlemiller KK, Roberts MS, Vogler CA, Sands MS (2001) Prevention of systemic clinical disease in MPS VII mice following AAV-mediated neonatal gene transfer. Gene Ther 8:1291-1298.

Drager UC (1985) Birth dates of retinal ganglion cells giving rise to the crossed and uncrossed optic projections in the mouse. Proc R Soc Lond B Biol Sci 224:57-77.

Dudus L, Anand V, Acland GM, Chen S-J, Wilson JM, Fisher KJ, Maguire AM, Bennett J (1999) Persistent transgene product in retina, optic nerve and brain after intraocular injection of rAAV. Vision Res 39:2545-2553.

Frisella WA, O'Connor LH, Vogler CA, Roberts M, Walkley S, Levy B, Daly TM, Sands MS (2001) Intracranial injection of recombinant adenoassociated virus improves cognitive function in a murine model of mucopolysaccharidosis Type VII. Mol Ther 3:351-358.

Fu H, Samulski RJ, McCown TJ, Picornell YJ, Fletcher D, Muenzer J (2002) Neurological correction of lysosomal storage in a mucopolysaccharidosis IIIB mouse model by adeno-associated virus-mediated gene delivery. Mol Ther 5:42-49.

Ghodsi A, Stein C, Derksen T, Yang G, Anderson RD, Davidson BL (1998) Extensive $\beta$-glucuronidase activity in murine central nervous system after adenovirus-mediated gene transfer to the brain. Hum Gene Ther 9:2331-2340

Grafstein B, Forman DS (1980) Intracellular transport in neurons. Physiol Rev 60:1167-1283.

Kornfeld S (1992) Structure and function of the mannose 6-phosphate/ insulin-like growth factor II receptors. Annu Rev Biochem 61:307-330.

Levy B, Galvin N, Vogler C, Birkenmeier EH, Sly WS (1996) Neuropathology of murine mucopolysaccharidosis type VII. Acta Neuropathol 92:562-568.

Neufeld E, Fratantoni J (1970) Inborn errors of mucopolysaccharide metabolism. Science 169:141-146.

O'Connor LH, Erway LC, Vogler CA, Sly WS, Nicholes A, Grubb J, Holmberg SW, Levy B, Sands MS (1998) Enzyme replacement therapy for murine mucopolysaccharidosis type VII leads to improvements in behavior and auditory function. J Clin Invest 101:1394-1400.

Ohlemiller KK, Vogler CA, Roberts M, Galvin N, Sands MS (2000) Retinal function is improved in a murine model of a lysosomal storage disease following bone marrow transplantation. Exp Eye Res 71:469-481.

Passini MA, Lee EB, Heuer GG, Wolfe JH (2002) Distribution of a lysosomal enzyme in the adult brain by axonal transport and by cells of the rostral migratory stream. J Neurosci 22:6437-6446.

Sands MS, Birkenmeier EH (1993) A single-base-pair deletion in the $\beta$-glucuronidase gene accounts for the phenotype of murine mucopolysaccharidosis type VII. Proc Natl Acad Sci USA 90:6567-6571.

Sands MS, Barker J, Vogler C, Levy B, Gwynn B, Galvin N, Birkenmeier EH (1993) Treatment of murine mucopolysaccharidosis type VII by syngeneic bone marrow transplantation in neonates. Lab Invest 68:676-686.

Sferra TJ, Qu G, McNeely D, Rennard R, Clark KR, Lo WD, Johnson PR (2000) Recombinant adeno-associated virus-mediated correction of lysosomal storage within the central nervous system of the adult mucopolysaccharidosis type VII mouse. Hum Gene Ther 11:507-519.

Skorupa AF, Fisher KJ, Wilson JM, Parente MK, Wolfe JH (1999) Sustained production of $\beta$-glucuronidase from localized sites after AAV vector gene transfer results in widespread distribution of enzyme and reversal of lysosomal storage lesions in a large volume of brain in mucopolysaccharidosis VII mice. Exp Neurol 160:17-27.

Stein CS, Ghodsi A, Derksen T, Davidson BL (1999) Systemic and central nervous system correction of lysosomal storage in mucopolysaccharidosis type VII mice. J Virol 73:3423-3429.

Vogler C, Birkenmeier EH, Sly WS, Levy B, Pegors C, Kyle JW, Beamer WG (1990) A murine model of mucopolysaccharidosis VII: gross and microscopic findings in beta-glucuronidase-deficient mice. Am J Pathol 136:207-217.

Vogler C, Sands MS, Galvin N, Levy B, Thorpe C, Barker J, Sly WS (1998) Murine mucopolysaccharidosis type VII: the impact of therapies on the clinical course and pathology in a murine model of lysosomal storage disease. J Inher Metab Dis 21:575-586.

Walkley SU (1998) Cellular pathology of lysosomal storage disorders. Brain Pathol 8:175-193.

Wolfe JH, Sands MS (1996) Murine mucopolysaccharidosis type VII: a model system for somatic gene therapy of the central nervous system. In: Gene transfer into neurones: towards gene therapy of neurological disorders (Lowenstein P, Enquist L, eds), pp 263-274. Essex, UK: Wiley.

Zolotukhin S, Byrne BJ, Mason E, Zolotukhin I, Potter M, Chesnut K, Summerford C, Samulski RJ, Muzyczka N (1999) Recombinant adenoassociated virus purification using novel methods improves infectious titer and yield. Gene Ther 6:973-985. 